\title{
Rescue surgery for bronchial obstruction after endovascular thoracoabdominal stent implantation
}

\author{
Philipp Kiefer, MD, ${ }^{\mathrm{a}}$ Joerg Seeburger, MD, ${ }^{\mathrm{a}}$ Lukas Lehmkuhl, MD, ${ }^{\mathrm{b}}$ and \\ Friedrich Wilhelm Mohr, MD, PhD, ${ }^{a}$ Leipzig, Germany
}

A 63-year-old woman had a diagnosis of aneurysm of the arch and the descending aorta. Medical history included a Bentall procedure for aortic regurgitation and ascending aortic aneurysm in 2006. The patient underwent redo surgery owing to progression of the diameter of the aneurysm. Replacement of the arch by the frozen elephant trunk technique with implantation of an E-vita prosthesis (JOTEC $\mathrm{GmbH}$, Hechingen, Germany) was performed. The procedure was completed with stent implantation (Valiant 42-200 mm; Medtronic, Inc, Minneapolis, Minn) in the descending aorta.

On postoperative day 34 the patient had severe dyspnea. A bronchoscopic examination showed a significant decrease of left main bronchus diameter to less than $2 \mathrm{~mm}$ owing to exterior compression. Computed tomography (CT) revealed a large hematoma around the endoprosthesis ranging from the distal part of the subclavian artery to the diaphragm (Figures 1 and 2). After an interdisciplinary discussion of the therapeutic options, the decision for surgery over bronchial stenting was made.

Surgery was performed with the patient in a right-sided position through a left minithoracotomy in the third intercostal space. Intraoperatively, a large and heavily tensioned aneurysmal sac of the descending aorta surrounding the E-vita prosthesis was opened with subsequent removal of the hematoma. The aneurysmal sac was left open to prevent development of subsequent hematoma. Multiple drains were inserted.

The postoperative course was uneventful with rapid respiratory weaning and the patient was discharged free of symptoms. Follow-up CT and bronchoscopy 1 month later showed a normal bronchus diameter.

\section{COMMENT}

We herein present an unusual case of bronchial obstruction after endovascular thoracoabdominal aortic aneurysm repair (EVAR). We believe that this case report is notable

\footnotetext{
From the Departments of Cardiac Surgery ${ }^{\mathrm{a}}$ and Radiology, ${ }^{\mathrm{b}}$ University of Leipzig, Heart Center, Leipzig, Germany.

Disclosures: Authors have nothing to disclose with regard to commercial support.

Received for publication Feb 9, 2011; revisions received April 26, 2011; accepted for publication May 17, 2011; available ahead of print June 27, 2011.

Address for reprints: Philipp Kiefer, MD, Heart Center, Leipzig University, Struempelstrasse 39, 04289 Leipzig, Germany (E-mail: p.kiefer@med.uni-leipzig.de). J Thorac Cardiovasc Surg 2011;142:1581-2

$0022-5223 / \$ 36.00$

Copyright (c) 2011 by The American Association for Thoracic Surgery doi:10.1016/j.jtcvs.2011.05.013
}

for 2 reasons: (1) to present a rare but potential highly dangerous complication of EVAR and (2) to describe successful surgical extirpation of a parastent hematoma.

EVAR is a routine procedure for the treatment of descending aortic aneurysms and type B dissections. It was introduced by Parodi, Palmaz, and Barone ${ }^{1}$ in the early 1990s. Since then, significant progress has been made with superior results, especially lower early mortality when compared with open surgical repair. $^{2}$

However, in several cases the procedure was unsuccessful owing to stent migration, the development of endoleaks, and the increase of aneurysmal diameter. ${ }^{3}$

With regard to this present case, only a few cases have been published in which stented aneurysms and their related pathologic conditions caused unusual symptoms such as hoarseness secondary to recurrent laryngeal nerve compression, diaphragmatic elevation secondary to phrenic nerve impingement, or bronchial compression. ${ }^{4}$ In these patients, symptoms are often misinterpreted and lead to diagnostic misdirection. However, even if diagnosed, little is known about reasonable treatment options.

In this present case, left main stem bronchial compression was caused by the increasing hematoma of the descending aorta. However, neither an endoleak with active bleeding nor migration of the prosthesis was detected with CT. A therapeutic regimen in such a case has not

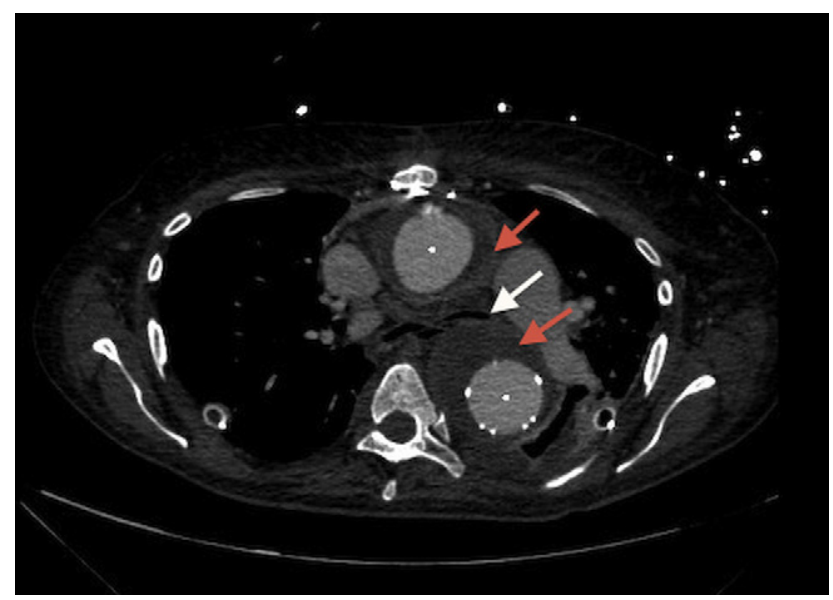

FIGURE 1. Compression of the left main bronchus (white arrow) by a hematoma surrounding the ascending and descending (red arrows) aorta after previous stent implantation, documented with a transversal slice by computed tomography. 


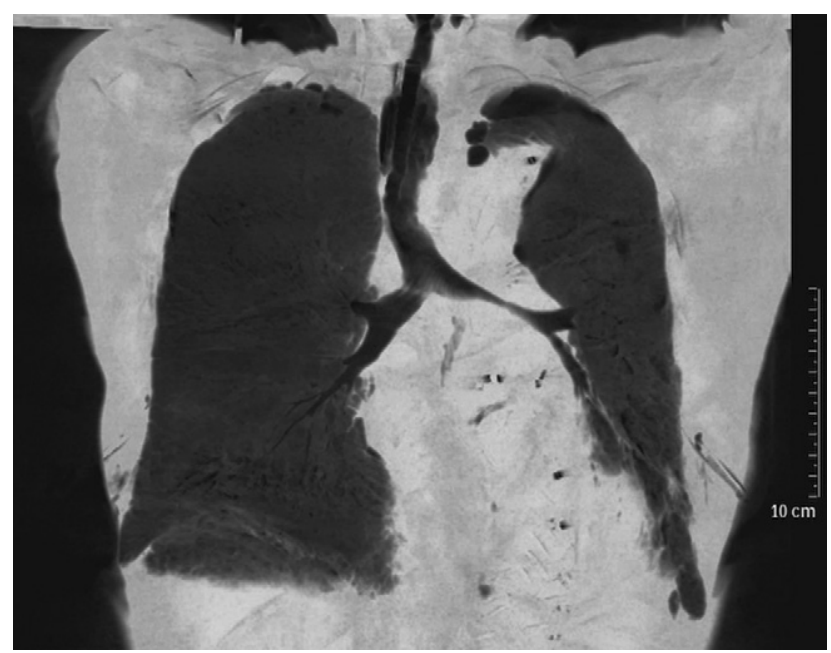

FIGURE 2. Minimum intensity projection showing compression of the left main bronchus. Minimum intensity projection demonstrates areas of lowest density, being equivalent to air. Other structures appear gray or black because of their density.

been described yet. Options could be open repair or dilatation with or without endobronchial stenting.

Madden, Loke, and Sheth ${ }^{5}$ reported a series of 31 patients undergoing bronchial stenting for airway compression. Clinical outcome was poor owing to obstructing granulation, mucus plugging, recurrent respiratory infections, and stent migration/fracture. Thus the value of stenting in airway compression is questionable and at best represents a palliative treatment. Another conceivable option for such patients is surgery. However, nothing has been reported so far, but a higher surgical risk can be anticipated owing to the potential for severe bleeding. In this case, to our understanding, the only reasonable access to the hematoma was the left-sided thoracotomy, which we were able to successfully perform.

\section{CONCLUSIONS}

Left-sided aortic aneurysmectomy is a reasonable option to treat bronchial compression after EVAR.

\section{References}

1. Parodi JC, Palmaz JC, Barone HD. Transfemoral intraluminal graft implantation for abdominal aortic aneurysms. Ann Vasc Surg. 1991;5:491-9.

2. Gopaldas RR, Huh J, Dao TK, LeMaire SA, Chu D, Bakaeen FG, et al. Superior nationwide outcomes of endovascular versus open repair for isolated descending thoracic aortic aneurysm in 11,669 patients. J Thorac Cardiovasc Surg. 2010; 140:1001-10.

3. Morales JP, Greenberg RK, Lu Q, Cury M, Hernandez AV, Mohabbat W, et al. Endoleaks following endovascular repair of thoracic aortic aneurysm: etiology and outcomes. J Endovasc Ther. 2008;15:631-8.

4. Morales JP, Chan YC, Bell RE, Reidy JF, Taylor PR. Endoluminal repair of distal aortic arch aneurysms causing aorto-vocal syndrome. Int J Clin Pract. 2008;62: 1511-4.

5. Madden BP, Loke TK, Sheth AC. Do expandable metallic airway stents have a role in the management of patients with benign tracheobronchial disease? Ann Thorac Surg. 2006;82:274-8.

\title{
Right ventricular exclusion for a neonatal patient with Ebstein anomaly: A free wall resection of the right ventricle
}

\author{
Takuya Kawabata, MD, PhD, Shingo Kasahara, MD, PhD, Sadahiko Arai, MD, PhD, and \\ Shunji Sano, MD, PhD, Okayama, Japan
}

The treatment of neonatal patients with severe Ebstein anomaly remains challenging for cardiac surgeons and pediatric cardiologists. The enlarged right side of the heart induces cardiopulmonary dysfunction. Since the first report

From the Department of Cardiovascular Surgery, Okayama University Graduate School of Medicine, Dentistry, and Pharmaceutical Sciences, Okayama, Japan. Disclosures: Authors have nothing to disclose with regard to commercial support. Received for publication Dec 7, 2010; revisions received May 2, 2011; accepted for publication May 23, 2011; available ahead of print July 1, 2011.

Address for reprints: Takuya Kawabata, MD, PhD, Department of Cardiovascular Surgery, Okayama University Graduate School of Medicine, Dentistry, and Pharmaceutical Sciences, 2-5-1 Shikata, Okayama, 700-8558, Japan (E-mail: ktakuya@pop01.odn.ne.jp).

J Thorac Cardiovasc Surg 2011;142:1582-4

$0022-5223 / \$ 36.00$

Copyright $(\odot 2011$ by The American Association for Thoracic Surgery doi:10.1016/j.jtcvs.2011.05.019 by Starnes, ${ }^{1}$ Reemtsen, ${ }^{2}$ and their coworkers, several evolutions of a single ventricular palliative operation have been reported. We herein describe a neonatal patient with Ebstein anomaly who underwent a free wall resection of the right ventricle $(\mathrm{RV})$ in combination with single ventricular palliative surgery.

\section{CLINICAL SUMMARY}

A male infant was born at 38 weeks' gestation by normal vaginal delivery with a birth weight of $2.55 \mathrm{~kg}$. Ebstein anomaly was diagnosed by fetal ultrasound cardiography (UCG). Postnatal UCG showed massive tricuspid regurgitation with plastering of the tricuspid septal and posterior leaflets, membranous pulmonary atresia, large atrial septal defect, compression of the left ventricle (LV) by the 